\title{
ЧРЕЗВЫЧАЙНОЕ ПРАВО КАК ОСОБЫЙ КОМПЛЕКСНЫЙ ПРАВОВОЙ ИНСТИТУТ
}

\begin{abstract}
Аннотация: В статье освещается проблема определения содержания и статуса чрезвычайного права как элемента системы российского права. Раскрываются особенности чрезвычайного права как института права. Автор обосновывает особый комплексныйхарактер чрезвычайного права как специфического правового института. По его мнению, определенное сдержсивающее значение могут иметь приниипы чрезвычайного права, закрепленные в законодательстве о чрезвычайном положении. Кроме того, в статье чрезвычайное право рассматривается в субъективном смыссле как предусмотренная нормами права возможность органов государственной власти использовать чрезвычайные меры в кризисных ситуациях, а также в объективном смысле чрезвычайное право представляет универсальный, комплексный правовой институт, регулирующий с помощью специфических правовых средств отношения, возникающие вусловиях исключительного положения. Автором сделан анализ чрезвычайного права как института права, который позволяет прийти к выводу о том, что институт чрезвычайного права - это не стандартный правовой институт, а своеобразное эксклюзивное явление в праве. Review: The article is devoted to the problem of contents and status of emergency law as an element within the system of Russian law. The author discusses specific features of emergency law as a specific legal institution. In his opinion the principles of emergency law, as provided for in the legislation on emergency situations, may have restraining value. Additionally, in the article emergency law is analyzed in its subjective aspect as legally provided ability of state government bodies to take emergency measures in the crisis situations, and in its objective aspect as a universal complex legal institution, regulating by specific legal means the relations appearing in the conditions of emergency situations. The author analyzes emergency law as a legal institution, and he makes a conclusion that this is not a standard legal institution, and rather a peculiar exclusive legal matter. Ключевые слова: чрезвычайное правовое регулирование, чрезвычайный правовой режим, чрезвычайное право, экстраординарный правовой режим, институт чрезвычайного права, чрезвычайные ситуации, чрезвычайное положение, чрезвычайные меры, функции чрезвычайного права, особенности чрезвычайного права
\end{abstract}

Keywords: emergency legal regulation, emergency legal regime, emergency law, extraordinary legal regime, emergency law institution, emergency situations, emergency, emergency measures, functions of emergency law, specific features of emergency law.

татус и место чрезвычайного права в системе российского права практически не выступали предметом серьезных научных исследований. Вопросы чрезвычайного положения по устоявшейся традиции затрагиваются специалистами в области конституционного права и административного права. Общим место является точка зрения, согласно которой режим чрезвычайного положения относится к административно-правовым режимам. Соответственно можно сделать вывод, что отраслевая принадлежность режима чрезвычайного положения связана с административным правом. Вместе с тем, ранее ученых не интересовал вопрос о предмете, функциях, методах и особенностях чрезвычайного права. К тому же и не бесспорно отнесение чрезвычайного права к отрасли административного права.

Говоря о предмете чрезвычайного права, следует иметь ввиду неоднородность тех отношений, которые регулируются нормами чрезвычайного права.
Во-первых, в круг регулируемых чрезвычайным правом отношений входят отношения, возникающие по поводу введения, продления и отмены режима чрезвычайного положения и иных экстраординарных правовых режимов. В силу особого значения этих отношений, они относятся к предмету конституционного права.

Во-вторых, предметом чрезвычайного права охватываются те отношения, которые складываются в условиях чрезвычайной ситуации и имеют патологический, нестабильный и кризисный характер.

Причем наряду с этими отношениями в ситуации чрезвычайного положения продолжают существовать и нормально функционировать иные общественные отношения, не изменившиеся в чрезвычайной ситуации. Эти отношения по-прежнему регулируются нормами тех отраслей права, в предмет которых они входили до возникновения чрезвычайной ситуации. Чрезвычайное право, как правило, не может, да и неспособно подменить ординарное правовое регулирование. Чрезвычайное 
право создает лишь изъятия из ординарного, обычного права, но не замещает нормальный правовой порядок. Так, при чрезвычайном правовом регулировании редко затрагиваются отношения в сфере частного права - семейного, гражданского и трудового права.

Можно сказать, что одновременно сосуществуют два вида правового регулирования - ординарное и экстраординарное, которое корректирует и изменяет отдельные институты ординарного права.

Итак, в предмет чрезвычайного права входят следующие общественные отношения:

- отношения между высшими органами государственной власти по поводу введения, продления и отмены чрезвычайного положения и иных исключительных правовых режимов;

- отношения, возникающие в условиях чрезвычайного положения и нуждающиеся в государственном контроле, охране и нормализации.

К особенностям чрезвычайного права как института права можно отнести:

1. Комплексный, межотраслевой характер чрезвычайного права, включающий нормы различных отраслей российского права, в большей степени административного и конституционного права;

2. По своему характеру чрезвычайное право-публичноправовой институт, направленный на охрану общества от угрозы чрезвычайных и иных кризисных ситуаций;

3. Среди методов в чрезвычайном праве превалирует императивные начала, а среди способов правового регулирования-запреты, обязывания, правоограничения;

4. Чрезвычайное право в обычных условиях находится в «спящем состоянии» и не применяется;

5. Чрезвычайное право влечет за собой кардинальное изменение порядка правового регулирования, перенастраивает правовую систему на преодоление чрезвычайной ситуации путем выхода за пределы, установленные законом для деятельности государства в нормальных условиях.

6. В определенном смысле чрезвычайное право - есть легализованное правонарушение, т.е. оно позволяет нарушить установленные нормы для мирного времени.

7. Нормы чрезвычайного права создаются и применяются специальными государственными институтами - чрезвычайными органами.

Говоря о чрезвычайном праве нужно различать две подсистемы в системе чрезвычайных правовых норм. Первая часть юридических норм создается заблаговременно, до наступления кризиса и касается порядка пере- хода к чрезвычайному правовому регулированию. Так, Федеральные Конституционные законы о чрезвычайном и военном положениях являются классическими примерами актов, которые содержат такие первичные чрезвычайные нормы ${ }^{1}$. По сути дела, первичные нормы касаются организационной основы перехода на экстраординарное правовое регулирование. По существу чрезвычайные отношения такие юридические нормы не регулируют.

Вторая же группа юридических норм появляется уже в условиях критической обстановки и направлена на регулирование конкретных отношений, возникших в связи с чрезвычайной ситуацией. И заблаговременно существо таких норм права предусмотреть практически невозможно. Чаще всего, вместо нормативного регулирования происходит индивидуальное и казуальное правовое регулирование кризисных отношений, что отчасти лишь оправдано с точки зрения нестандартности и индивидуальности возникающих случаев. Но, с другой стороны, именно регулирование на основе индивидуальных властных велений и угрожает злоупотреблениями и бесправием. Поэтому, казуальное правовое регулирование должно в максимальной степени опираться на общие нормы права.

В определенном смысле именно вторичные юридические нормы и образуют чрезвычайное право-право, появившееся в условиях чрезвычайных обстоятельств. Это право-спонтанно, стихийно, иногда хаотично и непредсказуемо, поскольку зависит от степени беспорядка в общественных отношениях.

С точки зрения правовой природы отнесение чрезвычайного права к институтам административного права оправдано только в плане используемых методов и способов правового регулирования. В целом, очевидно, институт чрезвычайного права носит комплексный характер, включает нормы различных отраслей российского и может в зависимости от ситуации касаться практически всех отношений, входящих в предмет правового регулирования 2 . В силу этого, чрезвычайное право имеет не просто межотраслевой характер, но и общеправовое, универсальное для всей системы права значение. Ко всему прочему проблема места чрезвычайного права еще осложняется дискуссионностью и нерешенностью вопроса о структуре российского права, сущности и видах правовых институтов ${ }^{3}$.

\footnotetext{
${ }^{1}$ См: Лобзинев В.В. Федеральный конституционный закон «О чрезвычайном положении»: Комментарий. - М.: Спарк, 2003.252 с.

${ }^{2}$ См: Баранов В.М., Поленина С.В. Система права, система законодательства и правовая система. - Н.Новгород, 2000.

${ }^{3}$ См: Байтин М.И., Петров Д.Е. Система права: к продолжению дискуссии // Государство и право. 2003. N 1.
} 
DOI: $10.7256 / 1811-9018.2013 .10 .9604$

При цитировании этой статьи сноска на dоі обязательна

\section{Право и политика $10(166) \cdot 2013$}

В силу общеправового значения чрезвычайного права традиционная концепция комплексных институтов права врядли к нему применима ${ }^{4}$. Так, С.С. Алексеев писалпо поводу комплексных институтов права: «комплексный (смешанный) правовой институтпредставляетсобой составную часть данной отрасли права, которая содержит в себе отдельные элементы метода правового регулирования иной отрасли права. Это институт права, ибо данная совокупность норм права является неотъемлемой частью определенной отрасли права. И вместе с тем это - комплексный институт, ибо в его состав входят элементы метода, характерные для другой отрасли. Таким образом, правовое содержание комплексного института в целом однородно и монолитно. Речь идет лишь о проникновении в общее, однородное, в целом единое образование отдельных элементов методов, присущих другим отраслям права»5.

В целом такой подход адекватен в отношении чрезвычайного права, но с оговоркой о том, что чрезвычайноеправо имеет универсальный охват и предполагает применение императивного метода к отношениям, входящим практически в предмет всех отраслей российского права: конституционного, административного, гражданского, трудового, экологического, земельного и других отраслей права.

Попросту отношения в чрезвычайной ситуации выбывают из под действия норм иных отраслей права и подчиняются единому публично-правовому институту. Так, законодательство позволяет вводить ограничения в гражданском оборотепо продаже алкогольных напитков, оружия и боеприпасов, наркотических и психотропных веществ, что предполагает внесение изъятий в действие гражданскоправовых норм относительно договора купли-продажи.

Зачастую в кризисных ситуациях происходит перераспределение правовых средств из сферы частного права в сферу публичного права. Резко сужается диспозитивность и автономия и расширяется императивность и авторитарность в правовом регулировании. Частные отношения приобретают публично-правовую окраску и начинают определяться нормами административного права. Так, например, в условиях распространения массовых заболеваний ограничивается свобода передвижения, торговля теми товарами, которые могут представлять угрозу для здоровья населения, вводятся иные карантинные мероприятия.

Анализ чрезвычайного права как института позволяет придти к выводу о том, что институт чрезвычайного права - это не стандартный правовой институт, а своеобразное эксклюзивное явление в праве. Причины тому следующие.

${ }^{4}$ См: Алексеев С.С. Структура советского права. — M., 1975.

${ }_{5}^{5}$ Алексеев С.С. Общие теоретические проблемы системы советского права. - М.: Издательство юридической литературы, 1961. С. 83.
Во-первых, предмет чрезвычайного права весьма широк и может охватывать практически все общественные отношения, регулируемые правом, в зависимости от сложившейся чрезвычайной ситуации. Только данные отношения перестают регулироваться традиционными методами и способами и переход под начало императивного метода правового регулирования.

Например, традиционная для гражданского права свобода договора может быть ограничена в условиях чрезвычайного положения, когда товары, производимые монополистом на рынке необходимы для обеспечения безопасности. Вследствие данного обстоятельства в ч. 2 ст. 527 Гражданского Кодекса Российской Федерации предусматривается, что заключение государственного или муниципального контракта является обязательным для поставщика (исполнителя) лишь в случаях, установленных законом, и при условии, что государственным или муниципальным заказчиком будут возмещены все убытки, которые могут быть причинены поставщику (исполнителю) в связи с выполнением государственного или муниципального контракта» ${ }^{6}$.

Во-вторых, институт чрезвычайного права - контраст ординарной системе права. Чрезвычайное право, если можно так выразиться, меняет полярность прямо на противоположную и приводит к приостановлению действия текущего законодательства. В обычных условиях чрезвычайное право не активно и не применяется, а срабатывает лишь в критических для общества обстоятельствах. Если большая часть иных юридических норм реализуется в нормальных условиях, то чрезвычайноеправо-«ммертворожденноеправо», не имеющее сиюминутной результативностиипользы. Этоправо кслучаю - ad hoc. Причем необходимость в чрезвычайном правовом регулировании может так и не появиться. Так, в Германии, несмотря на обширное чрезвычайное законодательство, так и не было поводов для применения чрезвычайного права.

К функциям чрезвычайного права как правового института следует отнести:

1. охранительную, т.е. защита общества от различного рода угроз;

2. превентивную, связанную с недопущением чрезвычайных ситуаций;

3. компенсационную, предполагающую восстановление ранее существовавшего правопорядка, социального мира;

4. идеологическую, направленную на мобилизацию социальных ценностей и установок общества ради преодоления кризисных ситуаций.

\footnotetext{
${ }^{6}$ Собрание законодательства РФ. 29.01.1996. N 5.ст. 410.
} 
Чрезвычайное право можно рассматривать не только в объективном смысле как правовой институт, но и в субъективном смысле как полномочие государства на применение экстраординарных и внеправовых мер для разрешения экстремальных ситуаций. Право на экстраординарные меры в критических обстоятельствах вытекает из самой природы власти.

Естественно, как и в случае с другими правами и полномочиями, возникает угроза злоупотребления таким чрезвычайным правом и установления порядка, влекущего массовые нарушения интересов граждан и переход к недемократическим политическим режимам. А.В. Грязнов по этому поводу отмечает: «Право чрезвычайного положения должно обеспечивать государству не только возможность реагирования на чрезвычайные ситуации посредством дискреционных полномочий, но и очерчивать объем, границы их реализации. Субъективное право конкретного должностного лица в процессе ликвидации последствий чрезвычайных ситуаций, предполагая возможность свободного избрания того или иного варианта поведения, должно быть законодательно ограничено пределами возможного вмешательства в сферу прав и свобод граждан»?

Как правило, содержание права на чрезвычайные меры в ограниченной форме отражаются в законодательстве. Можно констатировать, что чрезвычайноеправо в субъективном смысле чаще всегопредставляет собой нелагизованную дискрецию властных органовгосударства. Конкретноесодержание дискреционных полномочий четко неопределяется взаконодательстве ив основном формулируется как общее дозволениенапринятие необходимых мер реагирования на кризисную ситуацию исходя из ситуации экстраординарных обстоятельств.

Причем сфера свободного принятия решений в экстремальных ситуациях или дискреции находится в прямо пропорциональной зависимости от уровня дезорганизации и хаоса в общественной жизни. Чем выше уровень беспорядка, тем шире свобода для принятия государственной властью необходимых чрезвычайных мер. Соответственно, тем меньше такая властная деятельность носит правовой характер, поскольку не имеет четкой и конкретной юридической основы для обоснования соответствующих решений. Именно в таких условиях роста дезорганизации порядка и возникаете угроза перехода к использованию неправового насилия и установления диктатуры власти.

\footnotetext{
${ }^{7}$ Грязнов А. В. Особенности обеспечения конституционных прав и свобод граждан в условиях режима чрезвычайного положения: Вопросы теории и практики : Автореферат диссертации на соискание ученой степени кандидата юридических наук. - М.,1994. С. 6.
}

По-видимому, именно в таком, нелегализованном, фактическом праве на экстраординарные меры был уверен Президент РФ, который в 1993 г. серией Указов сначала прекратил деятельность Съезда народных и депутатов и Верховного Совета РСФСР, а потому ввел чрезвычайное положение без необходимых на то юридических оснований.

Президент РФ в своем Указе от 21 сентября 1993 г. «О поэтапной конституционной реформе в Российской Федерации» исходил не из положений законодательства, а из необходимости защиты воли народа и безопасности государства, которым противоречила деятельность Верховного Совета РСФСР, препятствовавшая проведении либеральных реформ в экономике. Обосновывая роспуск Верховного Совета РСФСР, Президент РФ указывал на мотивы своего решения: «Стремясь к ликвидации политического препятствия, не дающего народу самому решать свою судьбу; учитывая неудовлетворяющую парламентским стандартам качество работы Верховного Совета и Съезда народных депутатов Российской Федерации; принимая во внимание, что безопасность России и ее народов - более высокая ценность, нежели формальное следование противоречивым нормам, созданным законодательной властью...».

Очевидно, что Президент РФ прямо нарушил конституционные нормы и вышел за пределы своей компетенции. В Указе предусматривалось, что прерывается осуществление законодательной, распорядительной и контрольной функций Съездом народных депутатов и Верховным Советом РФ. Высшая юридическая сила среди нормативно-правовых актов придавалась Указам Президента. Прием приоритет Указов Президента ОФ был закреплен в отношении Конституции РФ.

Причем данный Указ Президента РФ был признан неконституционным Конституционным Судом в заключении от 21 сентября 1993 г. «О соответствии Конституции Российской Федерации действий и решений Президента РФ «О поэтапной конституционной реформе Российской Федерации» от 21 сентября 1993 г. № 1440 и Обращения к граждан России 21 сентября 1993 г. Кроме того, Конституционный Суд РФ признал такой Указа Президента РФ основанием для прекращения его полномочий. Следует отметить, что мнения судей тогда разделились. Не все судьи поддержали такое решение. Своеобразием отличалась позиций А.Л. Кононова, который отмечал, что сложилась тупиковая в правовом отношении ситуация, когда Президент РФ не имел полномочий по роспуску парламента, но фактически обстоятельства требовали от него таких действий.

А.Л. Кононов полагал возможным объяснить допустимость Указа Президента РФ о роспуске всех парламентских 
DOI: $10.7256 / 1811-9018.2013 .10 .9604$

При цитировании этой статьи сноска на dоі обязательна

\section{Право и политика 10 (166) • 2013}

учреждений России с точки зрения института необходимой обороны. Судья тогда писал в особом мнении: «исходя из общепризнанных принципов права любой вид юридической ответственности исключается при наличии крайней необходимости. Конституционный Суд, решая вопрос об ответственности Президента, не только не опроверг, но даже и не обсуждал основной аргумент, содержащийся в его Указе, - действовал ли Президент в ситуации крайней необходимости, когда «формальное следование противоречивым нормам, созданным законодательной ветвью власти» и дальнейшее промедление в разрешении возникшего кризиса угрожало безопасности государства и народа, демократическим преобразованиям и экономических реформам и эта угроза не могла быть устранена в сложившихся обстоятельствах другими средствами, а цена менее значима чем предотвращенный вред. Перечень защищаемых целей и ценностей в Указе Президента достаточно очевиден. Кроме того, Президент прямо сослался на свои конституционные обязанности по обеспечению государственной и общественной безопасности в стране, охране прав и свобод человека и гражданина, а также на реализацию воли народа, выраженной в референдуме 25 апреля 1993 г., убедительно подтвердившим доверие Президенту и его политическому курсу».

Однако, принятые экстраординарные меры он оправдывал необходимостью защиты более высоких ценностей, нежели соблюдение закона.

По нашему мнению, определенное сдерживающее значение могут иметь принципы чрезвычайного права, закрепленные в законодательстве о чрезвычайном положении. В таком случаепринципы будут выступать нормативным и нравственным критерием оценки экстраординарных властных решений и средством ограничения властных прерогатив государства.

Таким образом, чрезвычайное право в объективном смыслепредставляет универсальный, комплексный правовой институт, регулирующий с помощью специфических правовых средств отношения, возникающие в условиях исключительного положения. В структуру чрезвычайного права входит две группы норм права. Первая группа норм права (первичные нормы) регламентирую порядок введения, продления и отмены чрезвычайного положения, полномочия и виды чрезвычайных органов власти. Вторая группа норм (вторичные нормы права) - это правила, которые вводятся чрезвычайными органами власти в условиях существующей экстремальной ситуации.

Чрезвычайное право можно понимать в субъективном смысле как совокупность дискреционных полномочий государственной власти на применение чрезвычайных мер воздействия в кризисных ситуациях жизни общества.

\section{Библиография:}

1. Лобзинев В.В. Федеральный конституционный закон «О чрезвычайном положении»: Комментарий. - М.: Спарк, 2003.

2. Алексеев С.С. Общие теоретические проблемы системы советского права. - М.: Издательство юридической литературы, 1961.

3. Грязнов А. В. Особенности обеспечения конституционных прав и свобод граждан в условиях режима чрезвычайного положения: Вопросы теории и практики : Автореферат диссертации на соискание ученой степени кандидата юридических наук.-М.,1994.

4. Баранов В.М., Поленина С.В. Система права, система законодательства и правовая система. Н.Новгород, 2000.

5. Байтин М.И., Петров Д.Е. Система права: к продолжению дискуссии // Государство и право. 2003. N 1.

6. Алексеев С.С. Структура советского права. - М., 1975.

7. Собрание законодательства РФ. 29.01.1996. N 5. ст. 410.

8. Гуляихин В.Н. Правовой менталитет российских граждан // NB: Вопросы права и политики. - 2012. 4. - C. 108 - 133. DOI: 10.7256/2305-9699.2012.4.310. URL: http://www.e-notabene.ru/lr/article_310.html

\section{References (transliteration):}

1. Lobzinev V.V. Federal'nyi konstitutsionnyi zakon «O chrezvychainom polozhenii»: Kommentarii.-M.: Spark, 2003.

2. Alekseev S.S. Obshchie teoreticheskie problemy sistemy sovetskogo prava. - M.: Izdatel'stvo yuridicheskoi literatury, 1961.

3. Gryaznov A. V. Osobennosti obespecheniya konstitutsionnykh prav i svobod grazhdan v usloviyakh rezhima chrezvychainogo polozheniya :Voprosy teorii i praktiki : Avtoreferat dissertatsii na soiskanie uchenoi stepeni kandidata yuridicheskikh nauk.-M.,1994.

4. Baranov V.M., Polenina S.V. Sistema prava, sistema zakonodatel'stva i pravovaya sistema. - N.Novgorod, 2000.

5. Baitin M.I., Petrov D.E. Sistema prava: k prodolzheniyu diskussii // Gosudarstvo i pravo. 2003. N 1.

6. Alekseev S.S. Struktura sovetskogo prava. - M., 1975.

7. Gulyaikhin V.N. Pravovoi mentalitet rossiiskikh grazhdan // NB: Voprosy prava i politiki. - 2012. - 4. C. 108 - 133. DOI: 10.7256/2305-9699.2012.4.310. URL: http://www.e-notabene.ru//r/article_310.html 